Tackling the remaining attainment gap between students with and without immigrant background: an investigation into the equivalence of SES constructs

Jenny Lenkeit ${ }^{\mathrm{a}, \mathrm{b}, *}$, Daniel H. Caro ${ }^{\mathrm{b}}$, Steve Strand ${ }^{\mathrm{b}}$

${ }^{a}$ Research Institute of Child Development and Education, Amsterdam Centre for Inequality Studies, University of Amsterdam, The Netherlands

${ }^{b}$ Department of Education, Oxford University, United Kingdom

* Corresponding author: Nieuwe Prinsengracht 130, 1018 VZ Amsterdam, The Netherlands, e-mail: J.Lenkeit@uva.nl 


\title{
Tackling the remaining attainment gap between students with and without immigrant background: an investigation into the equivalence of SES constructs
}

\begin{abstract}
In England, as in many European countries, students with immigrant background exhibit lower educational attainment than those without immigrant background. Family socioeconomic status (SES) helps explain differences in educational attainment but a gap remains that differs in size for students from different immigrant backgrounds. While the explanatory repertoire for the remaining gap is broad, it has been neglected to comprehensively investigate whether family SES constructs are equivalent across students with and without immigrant background. Using data from the first wave of the CILS4EU study for England $(n=4,315)$, the paper applies exploratory structural equation modelling (ESEM) to evaluate measurement invariance of family background constructs across students without and with immigrant background, specifically Pakistani/Bangladeshi immigrant background. Results suggest differences in the structure of family SES indicators across groups and in their association with educational attainment. A complementary set of variables is suggested to enhance family SES indicators. Findings are relevant to researchers investigating educational inequalities related to immigrant background.
\end{abstract}

\section{Introduction}

In many European countries students with immigrant background ${ }^{\mathbf{1}}$ exhibit lower educational attainment than those without immigrant background (Dronkers \& Heus, 2012; Marks, 2005; Shapira, 2012). The evidence from international (e.g. Mullis,

\footnotetext{
${ }^{1}$ For the sake of consistency we refer to students with immigrant background as being either first, second or third generation immigrants throughout the paper, unless otherwise stated.
} 
Martin, Kennedy, \& Foy, 2007; OECD, 2010) and national studies (e.g. Lehmann \& Lenkeit, 2008 for Germany; Ohinata \& van Ours, 2012 for the Netherlands; Strand, 2014a for England) is compelling and presents a major challenge for policymakers and practitioners aiming to reduce educational inequalities.

In England, the educational attainments of students with Caribbean, African, Pakistani and Bangladeshi immigrant background are on average below that of students without immigrant background (e.g. DfES, 2006; Strand, 2010a). Part of this gap in attainment can be explained by students' family socioeconomic status (SES) (Dustmann, Machin, \& Schönberg, 2010; Wilson \& Burgess, 2005), but the size of the remaining attainment gap varies between students of different immigrant backgrounds and for the family SES indicators used (Kingdon \& Cassen, 2010; Strand, 2011, 2014a, 2014b; Wilson \& Burgess, 2005). Studies also point to a weaker association of family SES with educational attainment for students with immigrant background than for those without immigrant background (Kingdon \& Cassen, 2010; Strand, 2014a, 2014b).

The reasons for the differential effects of family SES across students with and without immigrant background are not fully understood. Language barriers may additionally be confounded with attainment (Dustmann et al., 2010; Strand, 2014a) or institutional discrimination may play a role (Gillborn, 2005; Strand, 2012). Also, other indicators (e.g., cultural and social capital variables) not represented by common family SES measures may be more relevant for students with immigrant background than for non-immigrant background students (Modood, 2005). Another reason may be that indicators are not equally indicative of family SES for students with and without immigrant background (Hobbs \& Vignoles, 2007).

This paper investigates the equivalence of family SES indicators across students with and without immigrant background and more specifically across the first and 
second generation of Pakistani/Bangladeshi immigrant background students and students without immigrant background. We analyse how the relationship between family SES constructs and educational attainment varies across those groups, and propose a new set of items to improve the equivalence of family SES measures across students with and without immigrant background. The paper therefore suggests an additional perspective for explaining the immigrant background attainment gap that remains even after accounting for family SES.

\section{Context setting: The immigrant background gap in educational attainment in England}

Students with immigrant background make up approximately a quarter $(24.5 \%)$ of the population in primary and secondary schools in England. The largest groups are students with Pakistani (4.2\%), African (3.2\%), Indian (2.6\%), Bangladeshi (1.7\%), and Caribbean (1.4\%) immigrant background (DFE, 2011). On average, parents of students with immigrant background from Pakistan, Bangladesh and the Caribbean have lower educational and occupational qualification levels than those of students without immigrant background, but Irish, Indian, African-Asian, Chinese and African immigrant background groups are more likely to have higher qualification levels than the group without immigrant background (Modood, 2005; Strand, 2011).

In primary school, students with Caribbean, African, Pakistani and Bangladeshi immigrant background on average lag behind their peers without immigrant background, whereas Chinese, Indian and Irish immigrant background students generally exhibit higher educational attainments (Dustmann et al., 2010; Strand, 2010a, 2010b). The pattern remains relatively stable in secondary school (Jackson, 2012; Rothon, 2007; Strand, 2011; Wilson \& Burgess, 2005). Evidence for differential attainment trajectories across immigrant background groups has also been found. 
Chinese and Indian immigrant background students exhibit larger gains than students without immigrant background (Dustmann et al., 2010; Wilson \& Burgess, 2005) as they advance from primary to secondary schooling, whereas Caribbean and Pakistani immigrant background students make relatively less progress (Wilson \& Burgess, 2005). But. around age sixteen Strand (2014a) finds that most immigrant background students (except those with Caribbean background) make more progress than nonimmigrant background students.

Because many families with immigrant background are heavily concentrated towards the bottom of the social structure, family SES indicators help explain attainment gaps related to immigrant background. Using data from the nationally representative LSYPE study (Longitudinal Study of Young People in England) Strand (2011) reports that $30 \%$ of the students without immigrant background are entitled to free school meals (FSM) compared to 36\% Caribbean, 37\% Mixed British and Caribbean, $40 \%$ of African, and $42 \%$ of Asian immigrant background students (see also Dustmann et al., 2010).

Family SES indicators alone, however, cannot explain the attainment gap related to immigrant background. Accounting for family SES reduces the gap but it remains significant for students with Caribbean, Pakistani and Bangladeshi immigrant background who underachieve and grow less in their skills while students with other immigrant backgrounds perform better than expected accounting for family SES (Jackson, 2012; Rothon, 2007; Strand, 2010a). This suggests an interaction between family SES and different immigrant backgrounds. But, different studies yield different results with regard to the explanatory role of family SES in the attainment gap between students without and with different immigrant backgrounds, depending on the family SES (e.g., FSM eligibility, parents' occupational status, neighbourhood deprivation, 
home ownership) and attainment indicators (e.g., test scores or GCSE pass scores) used.

\section{Explanations for the remaining gap}

When trying to explain the remaining attainment gap, scholars often discuss a range of individual and institutional factors, some of which shall be discussed here. For example, students' and parents' command of the majority language is assumed to be additionally confounded with educational attainment (Dustmann et al., 2010). But language difficulties cannot explain the gap alone because students with Caribbean immigrant backgrounds, for whom English is the first language perform worse than other immigrant background groups for whom English is not the first language (Jackson, 2012).

Sewell (1997), Haynes, Tikly and Caballero (2006) point out that unruly and antagonistic behaviour is part of urban street culture in which many boys with Caribbean and African immigrant background attach lower significance to educational attainment and success. This argument however fails to explain the remaining attainment gaps for students with other immigrant backgrounds, e.g. Pakistani background. Further, racial stereotyping and academic expectations of teachers within educational settings may be a relevant factor that leads to a rejection of school and academic related norms and values, especially for students of Caribbean and African immigrant background (Gillborn, 1990; Youdell, 2003). Modood (2003), however, argues that Asian students, too, experience racism (mainly from peers), but are less likely to reject school and educational success.

Further, parenting practices seem to be important for the educational attainment and progress of young children and these have been found to vary by immigrant backgrounds and family structure (Chan \& Koo, 2010; Phoenix \& Husain, 2007; Sylva, Melhuish, Sammons, Siraj-Blatchford, \& Taggart, 2004). 
The average quality of schooling that students with immigrant background receive is often discussed to account for the remaining attainment gap as they are more likely to attend schools whose population is socially disadvantaged (Cook \& Evans, 2000; Strand, 2014b; Wilson \& Burgess, 2005) and teacher characteristics have been found to be unequally distributed among more and less advantaged schools (Clotfelter, Ladd, \& Vigdor, 2004).

Another approach to explain the remaining attainment gap is to further examine the relevance and comprehensiveness of the indicators used to capture the complexities of the family's socioeconomic situation. In this context studies often invoke sociological concepts of economic, cultural and social capital constructs (Bourdieu, 1983) as an organising framework to distinguish and broaden the explanations of family SES influences on educational attainment. In this framework, economic capital is defined as the command families have over economic resources (ibid.). It comprises e.g. income and assets that can be transformed into money (so called exchange values). Cultural capital is represented by continuous dispositions embedded in the human mind and body, cultural goods and educational certifications. Bourdieu (ibid.) further describes social capital as the lasting network of institutionalized relationships (family relationships as well as formalized clubs). The members of the network profit from the capital owned by the group of people belonging to the network. Therewith relationships become beneficial as they secure material and symbolic profits.

Researchers have discussed the importance of cultural and social capital for the educational attainment of students with immigrant background. For example, many families with Chinese and South Asian background share highly positive attitudes and values towards education and parents enforce these values through encouragement, norm enforcements (e.g. strict homework times) and high educational and career 
aspirations for their children (Basit, 1997, 2012; Modood, 2012). Also, scarce economic capital is often mobilized to invest in children's education (e.g. private tuition, Saturday schools) independent of social class (Archer, 2006; Strand, 2011). For some disadvantaged families with immigrant background religion might be a source for high attitudes and values towards education, but the desire for social mobility seems to be more decisive (Shah, Dwyer, \& Modood, 2010).

Basit (1997), Modood (2005), Wilson and Burgess (2005) have pointed out that schooling and educational qualifications are seen as a means to social mobility, which seems to be independent of social class status (Archer, 2006; Basit, 2012). Education is understood as a tool to reverse the initial downward mobility experienced through migration for the next generation (Modood, 2012). In contrast, disadvantaged families without immigrant background tend to reject the formal education system as a means to attainment, as it may be viewed as irrelevant to their social realities (Dale, Shaheen, Kalra, \& Fieldhouse, 2002) or as "getting above your station" (Shah et al., 2010).

Further, scholars widely point out extended social networks of many immigrant background families that are less prominent for those without immigrant background. The close-knit and cohesive unit of the family is linked with the wider kinship and community (Basit, 1997; Goulbourne \& Solomos, 2003). These social resources are mobilized to transmit values and educational aspirations to the next generation (Basit, 2012; Modood, 2012; Modood et al., 1997), but also, e.g. to gain information about the education system and the changing demands of contemporary labour markets that can be difficult to acquire otherwise for non-English speakers (Shah et al., 2010). Immigrant background, thus, seems to present a layer of complexity to commonly defined family SES positions of the societal majority (Archer, 2006).

We acknowledge the potential relevance of all of these factors to explain the 
remaining attainment gap related to immigrant background. But, a) the constellation of economic and cultural capital (Archer, 2006; Strand, 2011) that seems to be specific to families with immigrant background, b) the implied differential meaning of e.g. extended family and kinship networks and their purposes for groups with and without immigrant background (Basit, 2012; Modood, 2012) as well as c) the differential effects of family SES across different immigrant background groups (Kingdon \& Cassen, 2010; Strand, 2014a) let us consider yet an additional explanation: The variables used to describe family SES are not equally indicative of SES across immigrant groups and, consequently, comparisons of the family SES construct and derived estimates (e.g., the attainment gap related to SES) might not be equivalent across these groups.

\section{Equivalence of family SES across different immigrant background groups}

Few studies explicitly critique the equivalence of family SES indicators across students with and without immigrant background. For example, Modood (2005) and Rothon (2007) discuss the equivalence of occupational status indicators for students with immigrant background. Upon immigration many families experience a downward social mobility, because their occupational and educational levels from the country of origin are not recognised and because they experience discrimination in the labour market (Modood, 2005; Rothon, 2007). Thus their occupational status does not reflect their educational levels in the country of origin and to this extent their values and attitudes towards education.

On the one hand, indicators of family economic capital such as FSM and occupational status do not capture the extent of social disadvantage as students with immigrant background more often live in larger households with mothers working at home (Modood, 2005; Modood et al., 1997). This means in extent fewer earners and more dependents in the household. On the other hand, in many families with South 
Asian immigrant background older employed sons and daughters often contribute to the family income (Basit, 1997). Proxy measures of family economic capital through indicators such as FSM and occupational status are hardly able to capture these complex constellations within and between groups of different immigrant background.

Empirical investigations into the equivalence of family SES indicators are scarce. In the UK Hobbs and Vignoles (2007) have noted, that FSM is not a good proxy for students' family SES across different family structures and employment constellations. And that FSM indicates different social background conditions for students with different immigrant background as it is more associated with single parenthood among non-immigrant, Caribbean and African immigrant background families than among Asian immigrant background families. In Sweden Hansson and Gustafsson (2011) find inconsistent results for family SES measurement invariance across students with and without immigrant background, but provide some support that indicators are not equally representative of family SES for those groups of students. Most significant differences were found for indicators of mother's education level and the number of books at home.

\section{Hypothesis and aim of the paper}

Previous results and a qualitative inquiry (see section 6) provide support for our hypothesis that SES indicators are not equivalent for students with immigrant background and students without immigrant background in England. The reason is that indicators are centred towards the non-immigrant group and are not adapted to the specific economic, cultural and social realities of students with immigrant background. Some aspects of immigration (e.g. translation of educational levels from the country of origin into occupational levels in the receiving country) may affect most families with immigrant background (Rothon, 2007). Others (e.g. importance of social networks) may 
differ in their relevance for families of different immigrant background (Modood, 2012).

Our purpose is twofold: first, to examine the equivalence of SES indicators across students with and without immigration background; second, to examine the equivalence of SES indicators across students without immigration background and students with Pakistani/Bangladeshi background, which is the largest immigrant group in England with profound economic and cultural discrepancies between country of origin and receiving country.

Importantly, we do not argue that the potential lack of equivalence is a limitation of the sociological concepts and their underlying theories, but rather it is related to the indicators used to operationalise these concepts. First, we will develop a family SES indicator following traditional operationalizations through measures characterizing parental educational levels, parental occupational prestige, and family wealth (Buchmann, 2002; Caro \& Cortés, 2012; Yang \& Gustafsson, 2004) and evaluate its measurement invariance across students without and with immigrant background, resp. Pakistani/Bangladeshi immigrant background.

Second, we will develop constructs of family economic, cultural and social capital inspired by well-established theories by Bourdieu and Passeron (1977), Bernstein (1971) and Coleman (1988) and evaluate their measurement invariance across immigrant background groups.

Third, we will compare the association between family SES, economic, cultural and social capital indicators and educational attainment across immigrant background groups. For the three groups we expect economic, cultural and social capital to explain a greater proportion of attainment variance than SES. But, since all constructs are assumed to be centred towards students without immigrant background, we still expect 
differences in their association with educational attainment across students without and with immigrant background.

Fourth, we will propose new indicators of economic, cultural and social capital.

\section{Exploration}

There is limited empirical support in the literature for our hypothesis. Thus, our research covers to some extent new ground. To explore the viability of our hypotheses we conducted a qualitative inquiry focusing on students and families from Pakistani/Bangladeshi immigrant background. Two groups participated in the inquiry: a) nine teachers, practising in five different urban schools with substantial amount of immigrant background students and b) three academic scholars investigating educational outcomes related to immigrant background. We used semi-standardized questionnaires with closed and open ended questions. Participants were asked whether from their experience common indicators of economic (e.g. parents occupational status, FSM), cultural (e.g. educational resources) and social capital (e.g. sport, club membership) constructs were equally indicative of these constructs for students with Pakistani/Bangladeshi immigrant background as they are for non-immigrant students and to provide reasons for their answers.

Participants, pointed towards the difficulty to translate educational qualifications to occupational status for families with immigrant backgrounds and that educational qualification levels therefore "(...) are likely to correlate less strongly with occupational position or income than for the population whose qualifications were obtained in the UK" (participant [P]1). Some considered father's employment status to be equally important for the Pakistani/Bangladeshi immigrant background group and the nonimmigrant background group. Others however, anticipated this characteristic to have differential meaning for the two groups. It was pointed out, that in terms of economic 
capital the father is the "most important member of the family" (P2), because "In many Asian cultures the father is the sole person in the family who is employed" (P3). Participants found it difficult to estimate the importance of mother's employment status for the economic capital of the family but stated that mothers with Pakistani/Bangladeshi immigrant background are less likely to work than nonimmigrant background mothers. Also, "While professional women in many middle class families work, some don't if there is no financial necessity. In some working class families, it's thought to be dishonourable if women work outside the home." (P4).

Participants congruently identified parents' educational qualifications levels as indicators of cultural capital (rather than economic capital because of the limitations to translate these to a respective occupational status) and parents' education levels were seen as relating to "(...) the extent of parental support for the student's own education." (P1). The number of books at home and reading books for pleasure were perceived as equally important indicators of cultural capital for both Pakistani/Bangladeshi and nonimmigrant background families, as one participant noted for example: "I think it [number of books at home] is just as meaningful for both [groups], although the books do not have to be English texts." (P5). It was difficult for participants to evaluate the importance of cultural activities (such as visits to the museum) as cultural capital indicators. Overall cultural activities are seen to distinguish families from different social backgrounds within each of the groups rather than to distinguish between the groups. Thus, equal to the non-immigrant group educated Pakistani/Bangladeshi immigrant background families engage more in cultural activities than less educated ones.

Similarly, some participants viewed parents' educational expectation and aspirations to be equally indicative for both groups. Others pointed towards higher 
aspirations of Pakistani/Bangladeshi immigrant background families regardless of their social background and suggested that higher levels of expectations and aspirations underpin a differential meaning for the two groups. Communication between parents and children about school related issues as a social capital indicator was congruently viewed as being equally important for both immigrant and non-immigrant background groups.

In sum, the results of the inquiry suggested differential meanings of some family SES indicators for students with Pakistani/Bangladeshi immigrant background and students without immigrant background: parents' educational levels and occupational status, mothers' employment situations and educational aspirations. We searched for further empirical evidence with data from a student survey in the following section.

\section{Methodological approach}

\subsection{Data and measures}

Data were sourced from the Children of Immigrants Longitudinal Survey in Four European Countries (CILS4EU; Kalter et. al., 2013). CILS4EU focuses on the intergenerational integration of children of immigrants in England, Germany, the Netherlands, and Sweden. In the first wave in 2010/2011, children were around 14 years old. Among other, the study collects comprehensive data on family background characteristics and assesses attainment in a language test. CILS4EU oversamples students with immigrant backgrounds. From an overall sample of 4,315 students administered in England 1,926 students provided sufficient information to categorize them as without immigrant background and 2,252 as with immigrant background. We use the following measures for the analysis. 


\section{Immigrant background}

Students are categorized based on information about students', parents' and grandparents' birthplace.

Students without immigrant background: Students who are born in England and who have two parents and four grandparents born in England. 1,926 students fall into this category.

Students with immigrant background (compendious group): Students who are either born outside of England themselves ( $1^{\text {st }}$ generation $)$ or have at least one parent $\left(2^{\text {nd }}\right.$ generation $)$ or one grandparent $\left(3^{\text {rd }}\right.$ generation $)$ born outside England. 2,252 students fall into this category.

Students with Pakistani/Bangladeshi immigrant background: Students who are either born in Pakistan or Bangladesh ( $1^{\text {st }}$ generation $)$ or who have at least one parent born in Pakistan or Bangladesh $\left(2^{\text {nd }}\right.$ generation $)$. The data only provides country specific information on the place of birth for the students and his/her parents. Therefore we can only identify $1^{\text {st }}$ and $2^{\text {nd }}$ generation Pakistani/Bangladeshi immigrant background students. 379 students fall into this category.

\section{Socioeconomic Status (SES)}

A single SES indicator operationalised using the following variables:

Father's and mother's education: A single variable reflecting the highest education of each parent. Response categories are: $0=$ no qualification; $1=$ primary school or similar foreign, $2=$ secondary school or similar foreign, $3=$ university.

Father's and mother's occupational status: A single variable reflecting the highest score of each parent on the International Socioeconomic Index of Occupational Status (ISEI; Ganzeboom, Graaf, \& Treiman, 1992). Scores range from 16 to 85, where higher values indicate higher occupational status. 
Home possessions index: A single score obtained by estimating a Rasch model on dichotomous items reflecting students' possession of an own computer, internet access, an own room, an own smartphone, an own TV, and an own console. Scores range roughly from -3.5 to 3.5 , with higher values indicating greater value of possessions at home.

Number of books at home: A single variable reflecting the number of books at home. Response categories are $1=0-25$ books, $2=26-100$ books, $3=101-200$ books, $4=201-500$ books, $5=$ more than 500 books.

The concepts of economic, cultural, and social capital were operationalised through the following variables. Models allowed for cross-loadings, that is, each variable could load on the three forms of capital.

\section{Economic capital}

Father's and mother's highest education

Father's and mother's highest occupational status

Father's and mother's employment status: single variables reflecting if each parent is currently having a job. Response categories are $0=$ no, $1=$ yes.

Home possession index

\section{Cultural capital}

Number of books at home

Read books: A single variable reflecting how often students read a book in their spare time. Response categories are: $1=$ never, $2=$ less often, $3=$ once or several times a month, $4=$ once or several times a week, 5=every day.

Go to concert: A single variable reflecting how often students go to a concert or DJ event in their spare time. Response categories are: $1=$ never, $2=$ less often, $3=$ once or 
several times a month, $4=$ once or several times a week, 5=every day.

Visit museum: A single variable reflecting how often students go to a museum in their spare time. Response categories are: $1=$ never, $2=$ less often, $3=$ once or several times a month, $4=$ once or several times a week, $5=$ every day.

Read newspaper: A single variable reflecting how often students read the newspaper in their spare time. Response categories are: $1=$ never, $2=$ less often, $3=$ once or several times a month, $4=$ once or several times a week, $5=$ every day.

\section{Social capital}

Parental educational expectations: A single variable reflecting the highest level of education that parents want the student to get. Response categories are: $1=$ no degree, 2=GCSE or similar, 3=A-levels or similar, 4=university degree.

Interest in achievement: A single variable reflecting students' agreement to the statement that their parents are interested in their grades and achievement. Response categories are: $1=$ strongly disagree, $2=$ disagree, $3=$ neither agree nor disagree, $4=$ agree, $5=$ strongly agree.

Positive feedback: A single variable reflecting students' agreement to the statement that their parents tell them that they are proud when the student is doing well in school. Response categories are: $1=$ strongly disagree, $2=$ disagree, $3=$ neither agree nor disagree, $4=$ agree, $5=$ strongly agree.

Encouragement: A single variable reflecting students' agreement to the statement that their parents encourage them to work hard for school. Response categories are: $1=$ strongly disagree, $2=$ disagree, $3=$ =neither agree nor disagree, $4=$ agree, $5=$ strongly agree.

Table A (see Appendix A) provides an overview of descriptive statistics of these variables by immigrant background. 


\section{Educational attainment}

Educational attainment was measured with an English language test that focused on students' lexicon. The implemented test used 25 synonym tasks, in which synonyms for a given word had to be found out of 5 alternative answers. For example, for the term "closed" a synonym had to be identified out of the following alternatives: "clear", "shut", "finished", "fallen" and "tired". Test items were scaled using item response theory. All 25 items are included in the language attainment scale $(\alpha=0.8)$, which was standardized to have a mean of $\mathrm{M}=500$ and a standard deviation of $\mathrm{SD}=100$.

\subsection{Analytical strategy}

SES constructs and measurement invariance tests were developed and conducted using exploratory structural equation modelling (ESEM) in Mplus 7.1. ESEM is a recent statistical development that integrates the properties of exploratory factor analysis (EFA) and confirmatory factor analysis (CFA). It produces fit indices, allows for factor cross-loadings, and measurement invariance tests (Marsh et al., 2009; Marsh, Liem, Martin, Morin, \& Nagengast, 2011). It has been shown to perform better than CFA, because the zero cross-loading restriction in CFA often leads to inflated interfactor correlations and model fit indices that fail to support valid constructs (Marsh et al., 2011). For example, it has been shown that ESEM produces better fit than CFA for models of cultural, social, and economic capital and that cross-loadings for certain variables are statistically and theoretically meaningful (Caro, Sandoval-Hernández, \& Lüdtke, 2013).

Our analyses compared and demonstrated the superiority of ESEM over CFA for construct development as well. Goodness of fit was evaluated with the comparative fit index (CFI), Tucker-Lewis index (TLI), and root mean square error of approximation 
(RMSEA). ${ }^{2}$ Subsequently measurement invariance tests were conducted using ESEM. We ran configural invariance models and tested weak and strong invariance (Marsh et al., 2010; Meredith, 1964). The configural invariance model or baseline model indicates the similarity of the overall pattern of parameters across groups with no restriction imposed on the parameters. The weak invariance test evaluates if factor loadings are invariant over groups. The strong measurement invariance test evaluates if the indicator means (i.e., the intercepts of responses to individual items) and factor loadings are invariant over groups. The forms of invariance tests are hierarchical: weak invariance is tested against configural invariance and strong invariance against weak invariance. CFI, RMSEA and SRMR (Standardized Root Mean Squared Residual) are commonly consulted to support or reject the measurement invariance assumption. For small (total $\mathrm{n}<300$ ) and unequal sample sizes invariance is supported when a change in the main criterion CFI is less than .005 complemented by a change in RMSEA of less than .010 or by a change in SRMR less than .025 . For larger (total $n>300$ ) and equal sample sizes invariance is supported when a change in the CFI is less than .010 complemented by a change in RMSEA of less than .015 or by a change in SRMR less than .030 (Chen, 2007). A construct that does not satisfy weak invariance is expected also not to satisfy strong invariance conditions that impose even more restrictions on factor parameters across groups. Finally, SEM was applied to evaluate the relationship between the family SES, economic, cultural and social capital constructs and educational attainment.

\footnotetext{
${ }^{2}$ Heuristically, values of TLI and CFI greater than 0.90 and 0.95 , respectively, reflect acceptable and excellent fit to the data, while for the RMSEA, values less than 0.05 and 0.08 reflect a close fit and a reasonable fit to the data (Marsh, Hau, \& Wen, 2004).
} 


\section{Results}

\subsection{Equivalence of the SES construct across different immigrant background groups}

The starting point of our analysis was to test for construct equivalence of SES. For the multi-group comparison between students without and with immigrant background, only small differences in the factor loadings, that is the strength of an item's relationship with the latent construct, could partly be observed (Table 1). Parents' educational levels, father's occupational status and the number of books had similar factor loadings on SES in both groups. But the factor loading for mother's occupational status was larger for the immigrant background group (0.54 vs. 0.46) and the home possession index loaded negatively for the group without immigrant background but was not related to the factor for the immigrant background group (0.05 vs. -0.14). Generally, data fit indices for both groups were dissatisfactory with TLI=.79, CFI=.88, RMSEA=.11 for the non-immigrant background group and TLI=.85, CFI=.91, RMSEA=.09 for the immigrant background group.

The configural invariance model indicated rather poor data fit across both groups (see Table 2). Fit indices indicated a further reduction in model fit from the configural to the weak invariance models, where CFI reduced from 0.89 to 0.87 and SRMR increased from 0.05 to 0.07 . Changes in fit indices were small but large enough to reject weak invariance according to the aforementioned criteria. Fit indices for the strong invariance tests were then also not acceptable.

*** INSERT TABLE 1 ABOUT HERE ***

*** INSERT TBALE 2 ABOUT HERE *** 
We then investigated the construct equivalence of SES for students with Pakistani/Bangladeshi immigrant background and those without immigrant background (Table 1). Descriptively, differences in factor loadings between the groups seemed overall more pronounced. Father's education, his occupational status and mother's occupational status had slightly higher factor loadings for the Pakistani/Bangladeshi immigrant background group than for the non-immigrant background group (0.73 vs. $0.68,0.56$ vs. 0.48 and 0.54 vs. 0.46 respectively), while the opposite was true for mother's education (0.61 vs. 0.71$)$. As in the previous comparison, larger differences in factor loadings were observed for the number of home possessions, which loaded negatively on the factor for the non-immigrant background group, but no relevant factor loadings were observed for the Pakistani/Bangladeshi immigrant background group (0.14 vs. 0.05 ). Further, in this group the number of books at home loaded less strongly on the SES factor (0.34 vs. 0.45$)$.

Differences in loadings were confirmed by measurement invariance tests. Fit indices changed substantially from the configural invariance to the weak invariance model (e.g., CFI reduced from 0.87 to 0.78 ), indicating that weak invariance for SES cannot be supported across students without immigration background and those with Pakistani/Bangladeshi immigrant background (see Table 2). As expected, the fit indices for the strong invariance tests were then also not acceptable.

Data fit indices for both groups were dissatisfactory with TLI=.79, CFI=.88, RMSEA=.11 for the non-immigrant background group and TLI=.81, CFI=.89, RMSEA $=.08$ for the immigrant background group. 


\subsection{Equivalence of economic, cultural and social capital constructs across different immigrant background groups}

We further investigated the equivalence of economic, cultural and social capital constructs across the different groups. Results are presented in Table 3. The model was fitted to data from each group.

For the comparison of students without and with immigrant background differences in the factor structure and loadings were observed. The largest differences were observed for the cultural capital items where reading books has a greater loading for students without immigrant background (i.e., 0.77 vs 0.54 ) and going to the concert a greater loading for students with immigrant background (i.e., 0.30 vs 0.10 ). Also, for the economic capital construct, mother's employment status has a larger loading for families with immigrant background (i.e., 0.38 vs 0.19). The cross-loading of home possessions with cultural capital was larger for students without immigrant background than for students with immigrant background (-0.31 vs. -0.15). And cross-loadings of parental educational expectations with the cultural capital factor were larger for the nonimmigrant group than for the immigrant background group (0.22 vs. 0.05).

Data of this model generally fitted the group without immigrant background $(\mathrm{TLI}=.84, \mathrm{CFI}=.90, \mathrm{RMSEA}=.06$ ) better than the group with immigrant background (TLI=.77, CFI=.86, RMSEA=.06). Weak invariance could not be supported: $\mathrm{CFI}$ reduced from 0.88 to 0.85 and SRMR increased from 0.04 to 0.06 from the configural invariance model to the weak invariance model (see Table 4).Strong invariance was then also rejected.

\footnotetext{
*** INSERT TABLE 3 ABOUT HERE ***

*** INSERT TABLE 4 ABOUT HERE ***
} 
The comparison between the non-immigrant group and the

Pakistani/Bangladeshi group produced similar results, but differences seemed more pronounced (see Table 3). Again, reading books exerted a greater loading on cultural capital for families without immigrant background (i.e., 0.77 vs. 0.47 ) and going to the concert (i.e., 0.49 vs. 0.10 ) and visiting the museum (i.e., 0.77 vs. 0.52 ) a greater loading for families with Pakistani/Bangladeshi background. As with the SES results, again here father's education had a larger loading for families with Pakistani/Bangladeshi background (i.e., 0.75 vs. 0.65 ) and mother's education a lower loading (i.e., 0.62 vs. 0.73 ).

Further, the cross-loading of home possessions with cultural capital was negative for students without immigrant background but not for the students with Pakistani/Bangladeshi background (i.e., -0.31 vs. 0.07). The cross-loading of father's occupational status with cultural capital is larger for students with Pakistani/Bangladeshi background (i.e., 0.20 vs. 0.11). And cross-loadings of social capital indicators with the economic capital factors are larger for students with Pakistani/Bangladeshi background, particularly for the social capital indicator of parental educational expectations whose loading on economic capital is 0.44 compared to 0.24 for the students without immigrant background.

Data of this model generally fitted the group without immigrant background (TLI=.84, CFI=.90, RMSEA=.06) better than the group with Pakistani/Bangladeshi immigrant background (TLI=.78, CFI=.86, RMSEA=.06).

Measurement invariance tests revealed that the weak invariance assumption was not supported by the model fit indices (see Table 4). CFI reduced from 0.89 to 0.78 and SRMR increased from 0.04 to 0.08 from the configural invariance model to the weak invariance model. Strong invariance was thus also rejected. 


\subsection{Associations of SES, economic, cultural and social capital with attainment across different immigrant background groups}

Table 5 presents regression coefficients of structural equation models (SEM) of language attainment on family SES constructs by immigrant group. Strictly speaking, coefficients between models are not comparable because the measurement and structural parts of models are group-specific (i.e., loadings are different for each of the three groups). But the standardization of coefficients allowed us to make some comparisons nevertheless.

\section{*** INSERT TABLE 5 ABOUT HERE***}

First attainment was regressed on SES. SES coefficients and variance explained (i.e., R-squared) were fairly similar across groups (see SES models). Important differences were however observed when we next regressed attainment on economic, cultural and social capital (ECS models). For students without immigrant background the family's socioeconomic background was mainly related to educational attainment through its cultural capital component (coefficient of 0.399) and less but significantly through its economic and social capital component (coefficients of 0.145 and 0.045 , respectively). For students with immigrant background the dimension driving the association with family background was economic capital (coefficient of 0.324) followed by the cultural capital component (coefficient of 0.194). Results for the Pakistani/Bangladeshi immigrant background students again differ from both these findings. In this group, attainment was substantially related to economic capital (coefficient of 0.415 ) and not significantly to either cultural or social capital. The economic, cultural and social capital model explained substantially more attainment variance for all groups. Variance explanation was largest for the non-immigrant group 
(22\%), followed by the Pakistani/Bangladeshi group (19\%), and the immigrant background group (17\%).

\subsection{Discussion of results}

Our empirical analysis provide some support that measurement of family SES indicators (SES, economic, cultural and social capital) is not invariant across students with immigrant background, those with Pakistani/Bangladeshi immigrant background and those without immigrant background.

Differences were more pronounced for students with Pakistani/Bangladeshi immigrant background. We had expected education levels to be less correlated with the economic capital because the translation of qualifications obtained in the country of origin to respective occupational status in the receiving country has been discussed to be problematic. But father's educational level exerted greater influence on the economic capital construct for the Pakistani/Bangladeshi group than for the non-immigrant group. Mother's education, however, was less relevant for the economic capital of students with Pakistani/Bangladeshi background. The more restricted access to education for women in Pakistan and Bangladesh could make it more difficult to translate educational into occupational levels and economic capital in extension. It thus seems that the indicator could be biased towards families without immigrant background (Hansson \& Gustafsson, 2013). The higher relevance of mother's occupational and employment status in Pakistani/Bangladeshi immigrant background families, seemed contra-intuitive at first. The literature (Modood, 2005) and our data (see Table A, Appendix A) suggested that Pakistani/Bangladeshi women are less often employed. Thus, if mothers in Pakistani/Bangladeshi families are employed, it seems to make all the more differences to the economic capital of the family compared to non-immigrant background group in which mother's employment is more common. 
Father's occupational status was related to economic and cultural capital for both the non-immigrant group and the Pakistani/Bangladeshi group, the loading being greater in the latter. Bernstein (1971) argued that linguistic codes associated with parental occupational status reflected different forms of embodied cultural capital: restricted linguistic codes are used by working class families and elaborated codes in middleclass families. This distinction might be more pronounced for Pakistani/Bangladeshi families.

Reading books and to a lesser extent the number of books at home were less important for students with Pakistani/Bangladeshi immigrant background to describe the cultural capital dimension. We follow Hansson and Gustafsson's (2013) interpretation, that this indicator is most likely biased towards the non-immigrant group as access to books in the home language and opportunity to bring large amounts of books to the receiving country may be restricted for families with immigrant background.

Parental educational expectations had only low associations with the social capital dimension. For students with Pakistani/Bangladeshi immigrant background the variable had a stronger relation to economic capital. This is somewhat contrary to the research literature which underlines the importance of educational aspirations and expectations for some immigrant background groups, related to their social rather than their economic capital (Basit, 2012; Modood, 2004). But social capital is a multidimensional concept that is difficult to capture with the data at hand.

Overall, the pattern of factor loadings suggests differences in the structure of SES indicators for the Pakistani/Bangladeshi group and the non-immigrant background group that are later confirmed with measurement invariance tests. That is, when calculating SES measures based on the entire sample (i.e., using the same set of 
loadings) it is possible that two students with equivalent SES scores but one without immigrant background and the other with Pakistani/Bangladeshi background differ in their actual SES. Thus, researchers should be cautious when comparing SES indicators and associations with educational attainment between immigrant groups (Borsboom, 2006; Chen, 2007).

Further, model fit indices suggest that family SES indicators are centred towards the non-immigrant background group whose data generally fitted the models better. The model including economic, cultural and social capital to predict attainment was able to explain more variance across all groups than the single SES model. But the association with family background was driven by different dimensions for students without immigrant background, with immigrant background and with Pakistani/Bangladeshi immigrant background (e.g., cultural capital and social capital did not play a role for the Pakistani/Bangladeshi group). It is possible that the reason is weak measurement of these dimensions for the group with immigrant background, as suggested by model fit indices, and not a substantive difference in the explanation of educational attainment. The next section suggests new indicators to enhance measurement of economic, cultural and social capital for the Pakistani/Bangladeshi group.

\section{New indicators to capture economic, cultural and social capital}

Participants in our exploratory inquiry were asked to name characteristics which they found specifically relevant for Pakistani/Bangladeshi immigrant background students, either related to economic, cultural and social capital constructs or independent of them.

\section{Economic capital}

For economic capital it was proposed to consider that fathers and/or mothers may have more than one paid job. Thus, collecting information on the occupational status of one 
of these jobs only, may underestimate the actual economic capital of the family, if a second job is pursued. For the description of a family's economic capital participants also considered it important to have information on whether or not a family owns or rents a house, whether they have a car, and e.g. a computer at home. Some of these items are included in other surveys. Participants further considered it important to ask whether the family could afford to go on holidays and if so outside the UK and/or even to the country of origin.

\section{Cultural capital}

To elaborate the indicators of cultural capital, parents' educational qualifications in the country of origin were considered important. These levels cannot directly be translated into an occupational status in the receiving country to adequately indicate economic capital. But, it was suggested they mirror the parent's affinity to education itself and in that sense indicate part of the family's cultural capital. Further, as an indicator of cultural affinity and economic status participants suggested to collect information about whether the family lived in a rural or urban region in the country of origin. Rural/urban origin not only indicates educational opportunities but also familiarity with cultural activities. Parental involvement with the school was also considered specifically important to describe Pakistani and Bangladeshi immigrant background families' interest in their children's education. Language barriers and unfamiliarity with the UK education system may prevent parents from supporting their children directly by giving advice or checking homework. Thus seeking opportunities to learn about children's school issues, as e.g. on parents' evenings, is an important indicator of parents involvement. A second strategy of dealing with barriers to directly support their children is to hire tutors. Yet, another aspect indicating cultural capital is whether or not and to what extent students are involved in extracurricular activities and how much 
parents encourage them to be so, as those activities often have an explicit educational (language course) or charitable (e.g. protection of the environment) goal. Further, asking about visits to public institutions for cultural activities such as attending presentations, recitals, or exhibitions could further indicate affinity to cultural activities that are independent of economic capital, since they are mainly free of cost.

\section{Social capital}

The variables used to construct social capital present a form of social capital that can be labelled as "within-nuclear family social capital" and focuses on students' academic interaction with parents. However, it has been suggested that other dimensions of social capital exist and may play a larger role for immigrant background students (Basit, 2012; Modood, 2004). Participants, too, pointed towards the importance of the extended family and community for students' educational success. "In families where parents themselves have little education, yet have high aspirations for their children, educated members of the extended family or family friends are regularly approached to help with educational matters such as choice of schools, GCSE options and so forth.” (P4).

Participants further pointed towards religion as a potential indicator of both social and cultural capital. It may reflect cultural capital because many religious beliefs cultivate the importance of education (Shah et al., 2010). Also, if religion is acted out publically, such as in the mosque and within a religious community it becomes an indicator of social capital, because the community provides further networks that may function as advisors and supporters for educational issues (Shah et al., 2010). 


\section{Summary}

\subsection{Discussion}

Differences in educational attainment between students with and without immigrant background are a major challenge for educational practitioners and policymakers alike, who are aiming to reduce educational inequalities. While family SES explains part of the differences, a gap between different immigrant background groups often remains unexplained. Many plausible causes at the individual, family and institutional level have been explored, but the comprehensiveness and equivalence of family SES constructs is commonly neglected in the explanatory repertoire.

Our results provided some support for the hypothesis that family SES constructs are not equivalent for students without and with immigrant background, resp. Pakistani/Bangladeshi immigrant background. While some variables were comparable in their affiliation and strength of association with factors (e.g. father's employment status), others revealed relevant differences (e.g. father's education, home possessions, reading books, going to concerts). The family economic, cultural and social capital constructs are better predictors of attainment than SES across the three groups, but their association with attainment differs substantially between the three groups.

Clearly, one needs to proceed with caution regarding the choice of variables used for constructing family background measures and using those measures to answer further research questions. Moreover, additional indicators seem necessary to supplement commonly used measures of economic, cultural and social capital in order to capture family background more comprehensively and equally well for students with and without immigrant background. The proposed new items provide a first step in this direction.

The findings of this study are not just of methodological importance. Rather they 
are important for investigations into attainment gaps between students without and those with different immigrant background. Differences in attainment that remain after accounting for a measure of family SES are prone to be linked with specific characteristics believed to be inherent to the immigrant background group which are often discriminatory or based on prejudices. This paper illustrates that one reason why family SES in many cases cannot fully explain differences between students without and with different immigrant backgrounds, might be that indicators used are not equivalent representations of family SES across different groups. Other indicators such as parenting styles and institutional discrimination may play a role to further explain the attainment gap. Further investigations are necessary, though, to evaluate the extent to which non-equivalent family SES indicators affect their relationship with attainment.

We have developed models of cultural, social, and economic capital. Another approach in the literature has been to explain the remaining attainment gap as an interaction between SES immigrant background. For example, Strand (2014a) has shown that low SES ethnic minority students do better than low SES White-British students because of parenting and aspiration factors, but high SES ethnic minority students still do worse than high SES White-British because of structural barriers.

\subsection{Limitations}

The paper has limitations that should not go unnoticed. One is that for the comparison of the Pakistani/Bangladeshi and non-immigrant group, sample sizes are substantially unequal and smaller for the former group. But, we referred to CFI as the main criteria and SRMR, both of which have been shown to be relatively independent of sample size (Chen, 2007). Moreover, we referred to different cut off points for equally and unequally sized samples to evaluate support or rejection of the measurement invariance assumption as recommended by Chen (2007) and others 
(Marsh et al. 2011).

Another is that we were not able to administer the proposed new items. Further research should evaluate whether measurement invariance improves once these items are considered and a gap related to migration background still persists. Also, additional in-depth interviews with students and parents of immigrant background groups may have further informed the development of new items.

Another limitation is that we were only able to test the equivalence of constructs for the Pakistani/Bangladeshi immigrant background group. Sample sizes of other immigrant background groups were too small to include them in the analysis. But results could certainly differ e.g. for students with Caribbean, African or Chinese immigrant background regarding the constellation and importance of indicators used to describe family economic, cultural and social capital.

Finally, another limitation is that we have measured social capital with variables relating to parental engagement in students' education. Social capital, however, is a broad, multidimensional concept (e.g., structural, relational, and resources) and our measures cover only one aspect of it. Further research should consider how other dimensions of social capital relate to structural differences between groups with and without immigrant background.

\section{References}

Archer, L. (2006). Challenging classes?: Exploring the role of social class within the identities and achievement of British Chinese pupils. Sociology, 40(1), 29-49.

Basit, T. N. (1997). "I want more freedom, but not too much": British Muslim girls and the dynamism of family values. Gender and Education, 9(4), 425-440. 
Basit, T. N. (2012). "My parents have stressed that since I was a kid": Young minority ethnic British citizens and the phenomenon of aspirational capital. Education, Citizenship and Social Justice, 7(2), 129-143.

Bernstein, B. B. (1971). Class, codes and control. Theoretical studies towards a sociology of language (Vol. 1). London: Routledge \& Kegan Paul.

Borsboom, D. (2006). When does measurement invariance matter? Medical Care, 44(11 Suppl 3), S176-81.

Bourdieu, P. (1983). Forms of capital. In J. E. Richardson (Ed.), Handbook of theory and research for the sociology of education (pp. 241-258). New York: Greenwood.

Bourdieu, P., \& Passeron, J.-C. (1977). Reproduction in education, society and culture. London: Sage Publications.

Buchmann, C. (2002). Measuring family background in international studies of education: Conceptual issues and methodological challenges. In N. R. Council (Ed.), Methodological advances in cross-national surveys of educational achievement (pp. 150-197). Washington, DC: National Academy Press.

Caro, D. H., \& Cortés, D. (2012). Measuring family socioeconomic status: An illustration using data from PIRLS 2006. IERI Monograph Series: Issues and Methodologies in Large-Scale Assessments, 5, 9-33.

Caro, D. H., Sandoval-Hernández, A., \& Lüdtke, O. (2013). Cultural, social, and economic capital constructs in international assessments: an evaluation using exploratory structural equation modeling. School Effectiveness and School Improvement, 1-18.

Chan, T. W., \& Koo, A. (2010). Parenting style and youth outcomes in the UK. European Sociological Review, 27(3), 385-399.

Chen, F. F. (2007). Sensitivity of goodness of fit indexes to lack of measurement invariance. Structural Equation Modeling: A Multidisciplinary Journal, 14(3), 464-504.

Clotfelter, C., Ladd, H. F., \& Vigdor, J. (2004). Teacher quality and minority achievement gaps. Durham.

Coleman, J. S. (1988). Social capital in the creation of human capital. American Journal of Sociology, 94, S95-S120.

Cook, M. D., \& Evans, W. N. (2000). Families or schools? Explaining the convergence in White and Black academic performance. Journal of Labor Economics, 18(4), 729-754. 
Dale, A., Shaheen, N., Kalra, V., \& Fieldhouse, E. (2002). Routes into education and employment for young Pakistani and Bangladeshi women in the UK. Ethnic and Racial Studies, 25(6), 942-968.

DFE. (2011). GCSE and equivalent attainment by pupil characteristics in England 2010/11. Statistical First release SFR 03/2012. London.

DfES. (2006). Ethnicity and Education. London:DfES. Retrieved from http://webarchive.nationalarchives.gov.uk/20130401151715/https://www.educatio n.gov.uk/publications/eOrderingDownload/DFES-0208-2006.pdf

Dronkers, J., \& Heus, M. De. (2012). Immigrants' children scientific performance in a double comparative design: The influence of origin, destination, and community (No. Discussion Paper Series, Nr. 13/12).

Dustmann, C., Machin, S., \& Schönberg, U. (2010). Ethnicity and educational achievement in compulsory schooling. The Economic Journal, 120(August), F272F297.

Ganzeboom, H. B. G., Graaf, P. M. D. E., \& Treiman, D. J. (1992). A standard International Socio-Economic Occupational Status Index of occupational status. Social Science Research, 21, 1-56.

Gillborn, D. (1990). Race, ethnicity and education: teaching and learning in multicultural schools. London: Unwin Hyman.

Gillborn, D. (2005). Education policy as an act of white supremacy: Whiteness, critical race theory and education reform. Journal of Education Policy, 20(4), 485-505.

Goulbourne, H., \& Solomos, J. (2003). Families, ethnicity and social capital. Social Policy and Society, 2(4), 329-338.

Hansson, Å., \& Gustafsson, J.-E. (2013). Measurement invariance of socioeconomic status across migrational background. Scandinavian Journal of Educational Research, 57(2), 148-166.

Haynes, J., Tikly, L., \& Caballero, C. (2006). The barriers to achievement for White/Black Caribbean pupils in English schools. British Journal of Sociology of Education, 27(5), 569-583.

Hobbs, G., \& Vignoles, A. (2007). Is free school meal status a valid proxy for socioeconomic status (in school research)? London: Centre for the Economic of Education, London School of Economics.

Jackson, M. (2012). Bold choices: How ethnic inequalities in educational attainment are suppressed. Oxford Review of Education, 38(2), 189-208.

Kalter, F., A. F. Heath, M. Hewstone, J. O. Jonsson, M. Kalmijn, I. Kogan, and F. van Tubergen (2013). Children of Immigrants Longitudinal Survey in Four European 
Countries (CILS4EU). GESIS Data Archive, Cologne, ZA5353 Data file Version 1.0.0, doi:10.4232/cils4eu.5353.1.0.0 (forthcoming).

Kingdon, G., \& Cassen, R. (2010). Ethnicity and low achievement in English schools. British Educational Research Journal, 36(3), 403-431.

Lehmann, R., \& Lenkeit, J. (2008). ELEMENT. Erhebung zum Lese-und Mathematikverständnis. Entwicklungen in den Jahrgangsstufen 4 bis 6 in Berlin. [ELEMENT. Survey for reading and mathematics literacy. Development in grades 4 to 6 in Berlin]. Berlin: Humboldt University of Berlin.

Marks, G. N. (2005). Cross-national differences and accounting for social class inequalities in education. International Sociology, 20(4), 483-505.

Marsh, H. W., Hau, K., \& Wen, Z. (2004). In search of golden rules: Comment on hypothesis-testing approaches to setting cutoff values for fit indexes and dangers in overgeneralizing Hu and Bentler's (1999) findings. Structural Equation Modeling: A Multidisciplinary Journal, 11(3), 320-341.

Marsh, H. W., Liem, G. a. D., Martin, a. J., Morin, a. J. S., \& Nagengast, B. (2011). Methodological measurement fruitfulness of exploratory structural equation modeling (ESEM): New approaches to key substantive issues in motivation and engagement. Journal of Psychoeducational Assessment, 29(4), 322-346.

Marsh, H. W., Lüdtke, O., Muthén, B., Asparouhov, T., Morin, A. J. S., Trautwein, U., \& Nagengast, B. (2010). A new look at the big five factor structure through exploratory structural equation modeling. Psychological Assessment, 22(3), 47191.

Marsh, H. W., Muthén, B., Asparouhov, T., Lüdtke, O., Robitzsch, A., Morin, A. J. S., \& Trautwein, U. (2009). Exploratory Structural Equation Modeling, integrating CFA and EFA: Application to students' evaluations of university teaching. Structural Equation Modeling: A Multidisciplinary Journal (Vol. 16, pp. 439476).

Meredith, W. (1964). Notes on factorial invariance. Psychometrika, 29, 177-185.

Modood, T. (2003). Ethnic differentials in educational performance. In D. Mason (Ed.), Explaining ethnic differences: changing patterns of disadvantage in Britain. Bristol: Open Press.

Modood, T. (2004). Capitals, ethnic identity and educational qualifications. Cultural Trends, 13(2), 87-105.

Modood, T. (2005). The educational attainments of ethnic minorities in Britain. In G. C. Loury, T. Modood, \& Steven M. Teles (Eds.), Ethnicity, social mobility, and public policy. Comparing the US and UK (pp. 288-308). Cambridge: Cambridge University Press. 
Modood, T. (2012). Capitals, ethnicity and higher education. In T. N. Basit \& S. Tomlinson (Eds.), Social inclusion and higher education (pp. 17-40). Bristol: The Policy Press.

Modood, T., Berthoud, R., Lakey, J., Nazroo, J., Smith, P., Virdee, S., \& Sharon Beishon. (1997). Ethnic minorities in Britain. London: Policy Studies Institute.

Mullis, I. V. S., Martin, M. O., Kennedy, A. M., \& Foy, P. (2007). PIRLS 2006 international report: IEA's Progress in International Reading Literacy Study in primary schools in 40 countries. Chestnut Hill, MA: Boston College.

OECD - Organisation for Economic Co-operation and Development. (2010). PISA 2009 Results: Overcoming Social Background (Vol. II). Paris: OECD.

Ohinata, A., \& van Ours, J. C. (2012). Young immigrant children and their educational attainment. Economics Letters, 116(3), 288-290.

Phoenix, A., \& Husain, F. (2007). Parenting and Ethnicity. York.

Rothon, C. (2007). Can achievement differentials be explained by social class alone?: An examination of minority ethnic educational performance in England and Wales at the end of compulsory schooling. Ethnicities, 7(3), 306-322.

Sewell, T. (1997). Black masculinity and schooling: How black boys survive modern schooling. Stoke on Trent: Trentham Books.

Shah, B., Dwyer, C., \& Modood, T. (2010). Explaining educational achievement and career aspirations among young British Pakistanis: Mobilizing "ethnic capital"? Sociology, 44(6), 1109-1127.

Shapira, M. (2012). An exploration of differences in mathematics attainment among immigrant pupils in 18 OECD countries. European Educational Research Journal, 11(1), 68-95.

Strand, S. (2010a). Banging your head on the ceiling: Socio-economic factors and their relationship to differential attainment in Southwark primary schools. London: Southwark Council.

Strand, S. (2010b). Do some schools narrow the gap? Differential school effectiveness by ethnicity, gender, poverty, and prior achievement. School Effectiveness and School Improvement, 21(3), 289-314.

Strand, S. (2011). The limits of social class in explaining ethnic gaps in educational attainment. British Educational Research Journal, 37(2), 197-229.

Strand, S. (2012). The White British-Black Caribbean achievement gap: Tests, tiers and teacher expectations. British Educational Research Journal, 38(1), 75-101. 
Strand, S. (2014a). Ethnicity, gender, social class and achievement gaps at age 16: Intersectionality and "getting it" for the white working class. Research Papers in Education, 29(2), 131-171.

Strand, S. (2014b). School effects and ethnic, gender and socio-economic gaps in educational achievement at age 11. Oxford Review of Education, 40(2).

Sylva, K., Melhuish, E., Sammons, P., Siraj-Blatchford, I., \& Taggart, B. (2004). The Effective Provision of Pre-School Education (EPPE) project: Final report. London, Department for Education and Skills.

Wilson, D., \& Burgess, S. (2005). The Dynamics of School Attainment of England's Ethnic Minorities (No. 05/130). Bristol.

Yang, Y., \& Gustafsson, J.-E. (2004). Measuring Socioeconomic Status at Individual and Collective Levels. Educational Research and Evaluation, 10(3), 259-288.

Youdell, D. (2003). Identity traps or how black students fail: the interactions between biographical, sub-cultural, and learner identities. British Journal of Sociology of Education, 24, 4-20.

\section{Appendix A}

***INSERT TABLE A ABOUT HERE***

Table 1: Factor loadings for SES, by immigrant background

\begin{tabular}{lccc}
\hline & \multicolumn{3}{c}{ Factor loadings } \\
\hline & $\begin{array}{c}\text { with immigrant } \\
\text { background } \\
(\mathrm{n}=2,220)^{*}\end{array}$ & $\begin{array}{c}\text { Pakistani/Bangladeshi } \\
\text { immigrant } \\
\text { background }(\mathrm{n}=371)^{*}\end{array}$ & $\begin{array}{c}\text { without } \\
\text { immigrant } \\
\text { background } \\
(\mathrm{n}=1,921)^{*}\end{array}$ \\
\hline Father's education & $\mathbf{0 . 6 9}$ & $\mathbf{0 . 7 3}$ & $\mathbf{0 . 6 8}$ \\
Mother's education & $\mathbf{0 . 7 4}$ & $\mathbf{0 . 6 1}$ & $\mathbf{0 . 7 1}$ \\
Mother's occupational status & $\mathbf{0 . 5 4}$ & $\mathbf{0 . 5 4}$ & $\mathbf{0 . 4 6}$ \\
Father's occupational status & $\mathbf{0 . 5 2}$ & $\mathbf{0 . 5 6}$ & $\mathbf{0 . 4 8}$ \\
Home possessions index & 0.05 & 0.05 & $\mathbf{- 0 . 1 4}$ \\
Number of books & $\mathbf{0 . 4 3}$ & $\mathbf{0 . 3 4}$ & $\mathbf{0 . 4 5}$ \\
\hline
\end{tabular}

*Sample sizes may vary from indications in section 7.1 because Mplus draws on available information using full information maximum likelihood (FIML)

Note: Numbers in bold indicate statistical significance (5\%). 
Table 2: Multi-group analysis, measurement invariance test for the SES model

CFI TLI NFP RMSEA SRMR

without vs. with immigrant background

$\begin{array}{llllll}\text { SES configural invariance (CFA) } & 0.89 & 0.82 & 36 & 0.10 & 0.05\end{array}$

$\begin{array}{llllll}\text { SES weak invariance (CFA) } & 0.87 & 0.87 & 25 & 0.08 & 0.07\end{array}$

$\begin{array}{llllll}\text { SES strong invariance (CFA) } & 0.86 & 0.85 & 26 & 0.09 & 0.06\end{array}$

without vs. with Pakistani/Bangladeshi immigrant background

$\begin{array}{llllll}\text { SES configural invariance (CFA) } & 0.87 & 0.78 & 36 & 0.10 & 0.05\end{array}$

$\begin{array}{llllll}\text { SES weak invariance (CFA) } & 0.78 & 0.77 & 25 & 0.11 & 0.08\end{array}$

$\begin{array}{llllll}\text { SES strong invariance (CFA) } \quad 0.79 & 0.78 & 26 & 0.10 & 0.07\end{array}$

Note: CFI = Comparative Fit Index; TLI = Tucker-Lewis Index; NFP = Number of

Freedom Parameter; RMSEA = Root Mean Square Error of Approximation; SRMR = Standardized Root Mean Residual 
Table 3: Factor loadings for economic, cultural and social capital, by immigrant background

\begin{tabular}{|c|c|c|c|c|c|c|c|c|c|}
\hline & \multicolumn{9}{|c|}{ Factor loadings } \\
\hline & \multicolumn{3}{|c|}{$\begin{array}{l}\text { with immigrant } \\
\text { background } \\
(\mathrm{n}=2,251)^{*}\end{array}$} & \multicolumn{3}{|c|}{$\begin{array}{l}\text { Pakistani/Bangladeshi } \\
\text { immigrant background } \\
(\mathrm{n}=371)^{*}\end{array}$} & \multicolumn{3}{|c|}{$\begin{array}{l}\text { without immigrant background } \\
\qquad(\mathrm{n}=1,926)\end{array}$} \\
\hline & F1 & $\mathrm{F} 2$ & F3 & $\mathrm{F} 1$ & $\mathrm{~F} 2$ & F3 & $\mathrm{F} 1$ & $\mathrm{~F} 2$ & F3 \\
\hline \multicolumn{10}{|l|}{ Economic capital (F1) } \\
\hline Father's education & 0.63 & 0.09 & 0.02 & 0.75 & -0.01 & -0.10 & 0.65 & 0.06 & 0.00 \\
\hline Mother's education & 0.77 & 0.03 & 0.04 & 0.62 & 0.07 & 0.08 & 0.73 & 0.03 & -0.01 \\
\hline Mother's occupational status & 0.55 & 0.05 & 0.04 & 0.55 & 0.01 & 0.00 & 0.46 & 0.06 & 0.06 \\
\hline Father's occupational status & 0.47 & 0.13 & -0.01 & 0.51 & 0.20 & 0.06 & 0.44 & 0.11 & 0.07 \\
\hline Mother's employment status & 0.38 & -0.06 & -0.05 & 0.28 & 0.04 & -0.09 & 0.19 & -0.01 & 0.07 \\
\hline Father's employment status & 0.23 & -0.07 & -0.01 & 0.22 & -0.02 & -0.03 & 0.18 & -0.03 & 0.03 \\
\hline Home possessions index & 0.11 & -0.15 & 0.07 & 0.01 & 0.07 & 0.02 & 0.02 & -0.31 & 0.10 \\
\hline \multicolumn{10}{|l|}{ Cultural capital (F2) } \\
\hline Number of books & 0.33 & 0.38 & 0.06 & 0.24 & 0.41 & 0.07 & 0.27 & 0.48 & 0.03 \\
\hline Read books & 0.03 & 0.54 & 0.07 & 0.14 & 0.47 & 0.02 & -0.03 & 0.77 & 0.03 \\
\hline Go to concert & 0.02 & 0.30 & -0.12 & -0.06 & 0.49 & -0.14 & 0.10 & 0.10 & -0.04 \\
\hline Visit museum & -0.04 & 0.68 & -0.03 & -0.05 & 0.77 & 0.02 & 0.05 & 0.52 & 0.01 \\
\hline Read newspaper & -0.06 & 0.41 & 0.10 & 0.01 & 0.43 & 0.14 & -0.09 & 0.30 & 0.05 \\
\hline \multicolumn{10}{|l|}{ Social capital (F3) } \\
\hline Parental educational expectations & 0.24 & 0.05 & 0.17 & 0.44 & -0.19 & 0.17 & 0.24 & 0.22 & 0.11 \\
\hline Interest in achievement & 0.04 & 0.01 & 0.69 & 0.12 & -0.03 & 0.65 & 0.03 & 0.02 & 0.75 \\
\hline Give positive feedback & -0.02 & 0.04 & 0.67 & -0.07 & 0.03 & 0.73 & 0.01 & 0.00 & 0.75 \\
\hline Encourage school work & 0.00 & 0.01 & 0.84 & -0.03 & 0.02 & 0.84 & -0.01 & 0.03 & 0.83 \\
\hline
\end{tabular}

*Sample sizes may vary from indications in section 7.1 because Mplus draws on available information using full information maximum likelihood (FIML). 
Note: Numbers in bold indicate statistical significance (5\%)

Table 4: Multi-group analysis, measurement invariance test for the economic, cultural and social capital (ECS) model

\begin{tabular}{lccccc}
\hline & CFI & TLI & NFP & RMSEA & SRMR \\
\hline Without vs. with immigrant background & & & & & \\
Configural invariance (ESEM) & 0.88 & 0.81 & 154 & 0.06 & 0.04 \\
Weak invariance (ESEM) & 0.85 & 0.82 & 99 & 0.06 & 0.06 \\
Strong invariance (ESEM) & 0.85 & 0.82 & 102 & 0.06 & 0.05 \\
\hline \multicolumn{7}{l}{} \\
Without vs. with Pakistani/Bangladeshi immigrant background & & \\
Configural invariance (ESEM) & 0.89 & 0.83 & 154 & 0.06 & 0.04 \\
Weak invariance (ESEM) & 0.78 & 0.75 & 99 & 0.07 & 0.08 \\
Strong invariance (ESEM) & 0.79 & 0.75 & 102 & 0.07 & 0.07 \\
\hline Note: CFI = Comparative Fit Index; TLI = Tucker-Lewis Index; NFP = Number of Freedom Parameter;
\end{tabular}

RMSEA = Root Mean Square Error of Approximation; SRMR = Standardized Root Mean Residual

Table 5: Model estimates for attainment by immigrant background group

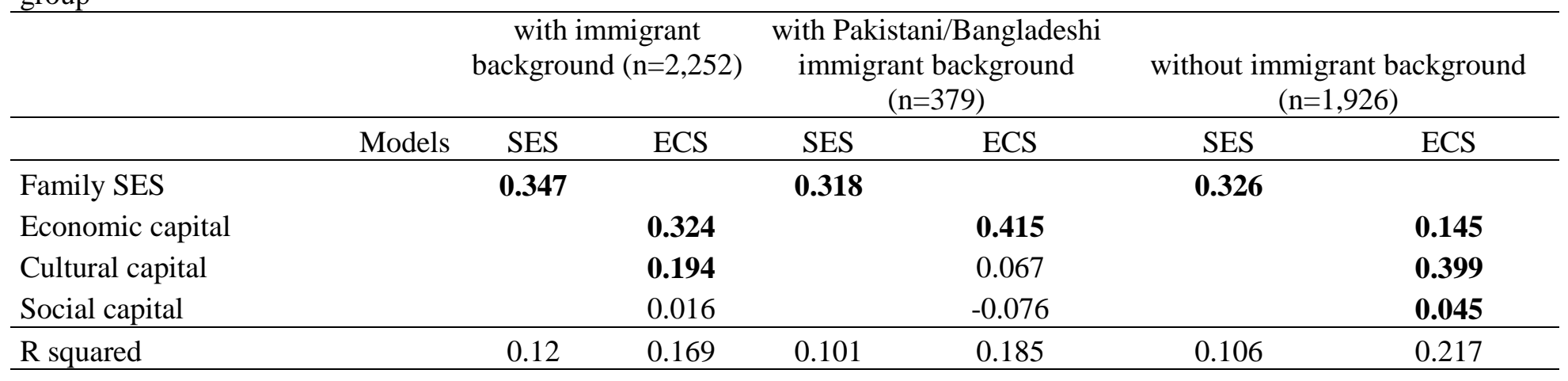

Note: Numbers in bold indicate statistical significance (5\%) 
Table A: Descriptive statistics of family background variables by immigrant background

\begin{tabular}{|c|c|c|c|c|c|c|}
\hline & \multicolumn{6}{|c|}{ Factor loadings } \\
\hline & \multicolumn{2}{|c|}{$\begin{array}{l}\text { with immigrant } \\
\text { background } \\
(\mathrm{n}=2,251)\end{array}$} & \multicolumn{2}{|c|}{$\begin{array}{c}\text { Pakistani/Bangladeshi } \\
\text { immigrant } \\
\text { background }(\mathrm{n}=371)\end{array}$} & \multicolumn{2}{|c|}{$\begin{array}{c}\text { without immigrant } \\
\text { background }(\mathrm{n}=1,926)\end{array}$} \\
\hline & $\mathrm{M}$ & SD & $\mathrm{M}$ & SD & $\mathrm{M}$ & SD \\
\hline \multicolumn{7}{|l|}{ Economic capital } \\
\hline Father's education & 2.11 & 0.82 & 1.85 & 0.93 & 1.92 & 0.77 \\
\hline Mother's education & 1.94 & 0.86 & 1.38 & 0.97 & 1.91 & 0.75 \\
\hline Mother's occupational status & 47.47 & 21.71 & 39.89 & 21.77 & 46.36 & 21.30 \\
\hline Father's occupational status & 48.28 & 23.08 & 40.94 & 19.80 & 45.74 & 23.15 \\
\hline Mother's employment status & 0.66 & 0.47 & 0.24 & 0.43 & 0.79 & 0.41 \\
\hline Father's employment status & 0.87 & 0.33 & 0.82 & 0.38 & 0.89 & 0.31 \\
\hline Home possessions index & 1.71 & 1.30 & 1.45 & 1.40 & 2.05 & 1.13 \\
\hline Computer at home $($ yes $=1$, no $=0$ ) & 0.83 & 0.38 & 0.83 & 0.38 & 0.85 & 0.36 \\
\hline Access of internet at home $($ yes $=1$, no $=0$ ) & 0.98 & 0.14 & 0.98 & 0.14 & 0.98 & 0.14 \\
\hline Own room $($ yes $=1$, no $=0)$ & 0.81 & 0.39 & 0.70 & 0.46 & 0.88 & 0.33 \\
\hline Own smartphone $($ yes $=1$, no $=0)$ & 0.58 & 0.49 & 0.53 & 0.50 & 0.54 & 0.50 \\
\hline Own TV (yes =1, no =0) & 0.59 & 0.49 & 0.49 & 0.50 & 0.81 & 0.39 \\
\hline Game console $($ yes $=1$, no $=0$ ) & 0.84 & 0.37 & 0.82 & 0.38 & 0.90 & 0.30 \\
\hline \multicolumn{7}{|l|}{ Cultural capital } \\
\hline Number of books & 2.43 & 1.25 & 1.89 & 1.08 & 2.45 & 1.24 \\
\hline Read books & 2.62 & 1.34 & 2.54 & 1.36 & 2.33 & 1.33 \\
\hline Go to concert & 1.82 & 0.86 & 1.60 & 0.86 & 1.91 & 0.85 \\
\hline Visit museum & 1.56 & 0.74 & 1.54 & 0.79 & 1.45 & 0.66 \\
\hline Read newspaper & 2.53 & 1.37 & 2.43 & 1.34 & 2.31 & 1.34 \\
\hline
\end{tabular}


Social capital

Parental educational expectations

$\begin{array}{lll}3.75 & 0.57 & 3.67\end{array}$

Interest in achievement

$\begin{array}{lll}3.75 & 0.57 & 3.67 \\ 4.46 & 0.76 & 4.49\end{array}$

Give positive feedback

$\begin{array}{lll}4.38 & 0.89 & 4.41\end{array}$

3.67
4.41
4.61

0.64

3.51

0.72

Encourage school work

$\begin{array}{llll}4.57 & 0.70 & 4.61 & 0.68\end{array}$ 